\title{
贵州月亮山不同演替阶段亮叶水青冈林碳储量及 其分配格局
}

周序力 蔡 琼 熊心雨 方文静 朱剑霄 朱江玲 方精云 吉成均*

北京大学城市与环境学院, 北京大学地表过程分析与模拟教育部重点实验室, 北京 100871

摘 要 林龄对森林生态系统碳储量及其在不同碳组分(植被、木质残体、调落物和土壤)中的分配有着重要影响。亚热带森 林在陆地生态系统碳循环中起着重要作用, 水青冈属(Fagus)植物是我国亚热带广泛分布的重要树种, 而有关水青冈林碳储 量随林龄变化的研究在我国鲜有报道。该研究选取贵州月亮山 3 个演替阶段(林龄分别为33年、82年和 208 年)的亮叶水青冈 (Fagus lucida) 林为研究对象, 对其生态系统全组分的碳储量及其分配格局进行了调查与估算。研究发现, 随林龄增加, 亮叶 水青冈林生态系统碳储量显著增加, 33年、82年和208年林分别为(186.9 \pm 46.0$) 、(265.8 \pm 82.3)$ 和(515.1 \pm 176.4$) \mathrm{Mg}^{\circ} \cdot \mathrm{hm}^{-2}$, 且 生态系统碳储量的增加主要由植被碳储量(占比由 $32 \%$ 增长至 $79 \%$ )贡献。调落物与木质残体碳储量随林龄增加亦呈增加趋势, 但二者占生态系统碳储量的比例很小 $(<1 \%)$ 。而不同林龄土壤碳储量无显著差异，其占比由 33 年林的 $67 \%$ 降至 208 年林的 $20 \%$ 。 这些结果验证了林龄对森林生态系统各组分碳储量及其分配的重要影响, 同时指出干扰和土地利用历史等对森林植物残体 和土壤碳积累的重要作用。

关键词 碳储量; 亮叶水青冈林; 林龄; 植被; 土壤; 调落物; 木质残体

周序力, 蔡琼, 熊心雨, 方文静, 朱剑霄, 朱江玲, 方精云, 吉成均 (2018). 贵州月亮山不同演替阶段亮叶水青冈林碳储量及其分配格局. 植物生态学 报, 42, 703-712. DOI: $10.17521 /$ cjpe.2018.0064

\section{Ecosystem carbon stock and within-system distribution in successional Fagus lucida forests in Mt. Yueliang, Guizhou, China}

ZHOU Xu-Li, CAI Qiong, XIONG Xin-Yu, FANG Wen-Jing, ZHU Jian-Xiao, ZHU Jiang-Ling, FANG Jing-Yun, and JI Cheng-Jun*

College of Urban and Environmental Sciences, and Key Laboratory for Earth Surface Processes of the Ministry of Education, Peking University, Beijing 100871, China

\section{Abstract}

Aims Stand age plays a vital role in carbon (C) stock and its distribution (vegetation, woody debris, litter and soil) within forest ecosystems. Subtropical forests are pivotal in the $\mathrm{C}$ cycling of terrestrial ecosystems. In subtropical China, Fagus trees are widely distributed and of great importance. However, the analyses of $\mathrm{C}$ storage in chronosequent Fagus forests have not been well performed.

Methods Nine Fagus lucida forests at three succession stages (33, 82 and 208 year-old) were studied in Mt. Yueliang, Guizhou Province, and their C stocks and distributions within the forests were investigated and estimated.

Important findings Ecosystem C stock increased significantly with increasing stand age, which was $(186.9 \pm$ 46.0), (265.8 \pm 82.3$)$ and $(515.1 \pm 176.4) \mathrm{Mg} \cdot \mathrm{hm}^{-2}$ in the 33, 82 and 208 year-old forests, respectively. The increase in the $\mathrm{C}$ stock appeared mainly attributed from increase in vegetation $\mathrm{C}$ stocks that accounted for $32 \%-79 \%$ of the total $\mathrm{C}$ stock. The woody debris and litter carbon stocks also increased significantly with increasing stand age, but accounted for $<1 \%$ of the total C stock. While soil C stock showed no significant change with increasing stand age, it decreased its contribution to the total C stock (from $67 \%$ to $20 \%$ ). These results confirmed the importance of stand age on $\mathrm{C}$ storage and the dynamic reallocations in the subtropical forests. Results from this study also added additional evidences in understanding the significance of disturbance and land use in $\mathrm{C}$

收稿日期Received: 2018-03-27 接受日期Accepted: 2018-05-12

基金项目：国家重点研发计划项目(2017YFA0605101)、国家科技基础性工作专项(2015FY210200)和国家自然科学基金(31700374)。Supported by the National Key Research and Development Program of China (2017YFA0605101), the National Science and Technology Basic Project of China (2015FY210200), and the National Natural Science Foundation of China (31700374).

* 通信作者Corresponding author (jicj@pku.edu.cn) 
accumulation.

Key words carbon stock; Fagus lucida forests; stand age; vegetation; soil; litter; woody debris

Zhou XL, Cai Q, Xiong XY, Fang WJ, Zhu JX, Zhu JL, Fang JY, Ji CJ (2018). Ecosystem carbon stock and within-system distribution in successional Fagus lucida forests in Mt. Yueliang, Guizhou, China. Chinese Journal of Plant Ecology, 42, $703-712$. DOI: $10.17521 /$ cjpe.2018.0064

全球森林碳储量达到 $861 \mathrm{Pg}\left(1 \mathrm{Pg}=10^{15} \mathrm{~g}\right)$, 并 以每年 $2.4 \mathrm{Pg}$ 的速度增长, 在缓解大气 $\mathrm{CO}_{2}$ 浓度升 高方面具有重要作用(Pan et al., 2011)。未受人类活 动干扰的森林生态系统碳库包括植被、木质残体、 调落物和土壤碳库(IPCC, 2013)。这些碳库受到诸多 环境因子的影响，如森林类型(张全智和王传宽， 2010)、林龄(Pregitzer \& Euskirchen, 2004)、温度与 降水(Aplet \& Vitousek, 1994)等。其中, 林龄对各组 分碳储量的影响至关重要(Gower et al., 1997; Pregitzer \& Euskirchen, 2004; Zhu et al., 2017a)。

已有不少研究探讨不同林龄森林的碳储量及其 分配格局的变化。研究对象多为局域某一类型森林 的林龄序列, 如大兴安岭 15-138年落叶松 (Larix gmelinii)林 (Zhu et al., 2017b), 广西7-32年格木 (Erythrophleum fordii)林(明安刚等, 2014), 韩国庆 尚北道10-71年赤松(Pinus densiflora)林(Noh et al., 2010)和加拿大安大略南部2-65年北美乔松 (Pinus strobus)林(Peichl \& Arain, 2006)等。也有全球尺度的 研究, 如Pregitzer和Euskirchen (2004)整合分析了全 球200年以下针叶林、温带与热带森林碳储量随林龄 变化的情况。以往的研究表明, 在一定年龄范围内, 随林龄增加, 森林生态系统碳储量和植被碳储量通 常呈增加趋势, 调落物和木质残体也会随之变化 (Hooker \& Compton, 2003; Pregitzer \& Euskirchen, 2004; Peichl \& Arain, 2006; Li et al., 2011; Zhu et al., 2017b)。而对于土壤碳储量, 随林龄增加通常也表 现为碳积累过程(Hooker \& Compton, 2003; Pregitzer \& Euskirchen, 2004; Zhu et al., 2017b), 然而林龄对 土壤碳积累的作用可能受到土地利用历史、气候和 植被类型等多种因素的影响, 故随演替进行, 土壤 碳储量也可能不变或呈现先减少后增加的趋势 (Peichl \& Arain, 2006; Nave et al., 2010; Li et al., 2011)。在碳储量的分配方面, 随演替进行, 通常植 被碳储量贡献增加, 而土壤碳储量贡献减小(Pregitzer \& Euskirchen, 2004; Peichl \& Arain, 2006; Zhu et al., 2017a)。但这些研究多针对人工林或中高纬度地 区的针叶林, 有关亚热带天然阔叶林生态系统碳储
量及其分配格局在不同演替阶段的变化目前仍鲜有 报道(宫超等, 2011)。

亚热带森林在陆地生态系统碳循环中起着重要 作用。有研究表明, 仅东亚季风区亚热带森林(占全 球森林面积的 5\%)的净生态系统生产力 (NEP) 就占 全球森林 $N E P$ 的 $8 \%$ (Yu et al., 2014)。水青冈属 (Fagus)植物是中国暖温带与亚热带地区广泛分布 的落叶阔叶乔木，也是欧洲、北美和日本落叶阔叶 林的代表性树种, 水青冈林是北半球重要的森林类 型(Wang \& Fujiwara, 2003; Fang \& Lechowicz, 2006)。对于水青冈林的碳储量和生产力, 国外已有 大量研究(Kakubari, 1991; Mund, 2004), 而在我国, 水青冈林碳储量的相关研究几乎未见报道。在贵州 月亮山, 集中分布着大片处于不同演替阶段的亮叶 水青冈(Fagus lucida)天然林(杨业勤, 1994), 这在我 国水青冈其他分布区较为少见, 为研究不同演替阶 段水青冈林碳库结构提供了理想的对象, 同时对了 解我国亚热带森林结构与功能随林龄的变化也具有 一定的参考意义。因此, 我们选择月亮山 3 个不同演 替阶段(33年、82年和208年)的9个亮叶水青冈林为 调查对象, 对样方内植被、土壤、木质残体和调落 物 4 个组分的碳储量进行了测定与估算, 旨在探讨 不同演替阶段亮叶水青冈林生态系统的碳储量及其 分配格局的变化。

\section{1 材料和方法}

\section{1 样地信息}

研究地点位于贵州省黔东南州榕江县月亮山省 级自然保护区 $\left(108.22^{\circ}-108.32^{\circ} \mathrm{E}, 25.57^{\circ}-25.65^{\circ}\right.$ $\mathrm{N})$ 。月亮山地处贵州省东南部, 位于华南褶皱带, 地质构造属新华夏体系, 基岩多为浅变质黏土岩类, 地貌类型为强切割侵蚀构造中低山。该区域属于亚 热带山地季风气候, 年平均气温12.1-15.7 ${ }^{\circ} \mathrm{C}$, 年降 水量1030-1 $688 \mathrm{~mm}$ 。地带性植被为常绿阔叶林, $1100 \mathrm{~m}$ 以上主要为常绿落叶阔叶混交林, 土壤多 为山地黄棕壤。月亮山低山地区受砍伐和放牧等人 为活动干扰较大, 而中山常绿阔叶混交林保存相对 
完好。亮叶水青冈林是该区域常绿阔叶混交林中主 要的森林类型(杨业勤, 1994; 吴开岑等, 2013; 张亚 冰等, 2016)。

2017年6月, 我们在海拔 1400-1 474 m范围内, 选取了 3 个不同演替阶段(平均林龄分别为 33 年、 82 年和 208 年)的亮叶水青冈林样地, 每个样地设置 3 个重复样方 $(20 \mathrm{~m} \times 30 \mathrm{~m})$ 。9个亮叶水青冈样方中, 3 个 33 年亮叶水青冈样方为天然次生林, 20 世纪 80 年 代砍伐后天然更新, 其余样方均为原始林。该区域 土壤深度约为 $30 \mathrm{~cm}$ 。在本研究中, 33 年林乔木层主 要树种有亮叶水青冈、贵州桤叶树(Clethra kaipoensis)和中华枫(Acer sinense)等, 88年林主要树种 有亮叶水青冈、多脉青冈(Cyclobalanopsis multinervis)和尖叶四照花(Dendrobenthamia angustata)等, 208年林主要树种有亮叶水青冈、多脉青冈和杜鹃 (Rhododendron sp.)等。样方基本信息见表 1 。

\section{2 野外调查及数据获取}

记录每个样方的经纬度、海拔、坡向、坡度等 基本信息, 对样方内植被(包括乔木层、灌木层和草 本层)、木质残体、调落物和土壤的碳密度 $\left(\mathrm{Mg} \cdot \mathrm{hm}^{-2}\right)$ 分别进行调查和估算。

\subsection{1 林龄测定}

在样方内选取 10 株胸径最大的亮叶水青冈, 在 1.3 米处利用生长雉从两个垂直的方向进行树芯采
集。样品带回实验室, 粘贴打磨, 用交叉定年法确定 树木的年龄, 取两个方向的平均值作为每株树的年 龄。将每个样方内亮叶水青冈年龄的最大值作为该 样方水青冈林的林龄。

\subsection{2 植被碳储量}

测量样方内所有胸径 $\geqslant 3 \mathrm{~cm}$ 活立木的胸径和树 高, 并记录物种名。利用相关生长方程计算每株树 的生物量, 其中乔木层地上生物量为乔木茎、枝和 叶生物量的总和, 乔木层地下生物量为乔木根生物 量。由于保护区内禁止砍伐, 无法对样地内树种进 行生物量方程构建, 故通过文献检索, 利用邻近地 区或气候条件相近地区对应树种的生物量方程(邱 学忠等, 1984; 邓仕坚等, 2000; 姚迎九等, 2003; 王 向雨等, 2007; 明安刚等, 2012)。以 0.5 作为碳转换系 数将树木生物量换算为生物量碳(Myneni et al., 2001; Zhu et al., 2015)对样地内不同树种的生物量 进行估算, 具体见表2。将样方内所有乔木生物量碳 加和后, 根据样方面积计算单位面积的碳储量(碳 密度, $\mathrm{Mg} \cdot \mathrm{hm}^{-2}$ )。

在样方内随机选取 3 个 $2 \mathrm{~m} \times 2 \mathrm{~m}$ 的小样方, 连 根收割小样方内所有灌木和草本, 测定鲜质量, 并 取样带回实验室, 在 $65{ }^{\circ} \mathrm{C}$ 烘干至恒质量后, 测定含 水率, 分别计算其地上生物量和地下生物量。灌木和 草本层样品经研磨后用元素分析仪(2400IICHNS/O,

表1 贵州月亮山水青冈林 9 个样方样地信息表

Table 1 Characteristics of the nine stands of Fagus lucida forest in Mt. Yueliang

\begin{tabular}{|c|c|c|c|c|c|c|c|c|c|}
\hline \multirow[t]{2}{*}{ 样地编号 Stand No. } & \multicolumn{3}{|c|}{ 33年林 33 a forest } & \multicolumn{3}{|c|}{82 年林 82 a forest } & \multicolumn{3}{|c|}{ 208年林 208 a forest } \\
\hline & YLS 1 & YLS 2 & YLS 3 & YLS 4 & YLS 5 & YLS 6 & YLS 7 & YLS 8 & YLS 9 \\
\hline 海拔 Altitude (m) & 1422 & 1400 & 1405 & 1457 & 1451 & 1439 & 1474 & 1471 & 1469 \\
\hline 森林起源 Forest origin & $\begin{array}{c}\text { 次生林 } \\
\text { Secondary } \\
\text { forest }\end{array}$ & $\begin{array}{c}\text { 次生林 } \\
\text { Secondary } \\
\text { forest }\end{array}$ & $\begin{array}{c}\text { 次生林 } \\
\text { Secondary } \\
\text { forest }\end{array}$ & $\begin{array}{c}\text { 原始林 } \\
\text { Primeval } \\
\text { forest }\end{array}$ & $\begin{array}{c}\text { 原始林 } \\
\text { Primeval } \\
\text { forest }\end{array}$ & $\begin{array}{c}\text { 原始林 } \\
\text { Primeval } \\
\text { forest }\end{array}$ & $\begin{array}{c}\text { 原始林 } \\
\text { Primeval } \\
\text { forest }\end{array}$ & $\begin{array}{c}\text { 原始林 } \\
\text { Primeval } \\
\text { forest }\end{array}$ & $\begin{array}{c}\text { 原始林 } \\
\text { Primeval } \\
\text { forest }\end{array}$ \\
\hline 林龄 Stand age (a) & 30 & 36 & 34 & 71 & 84 & 92 & 203 & 215 & 207 \\
\hline 坡向 Aspect & $\begin{array}{c}\text { 南偏东 } 80 \text { 度 } \\
80^{\circ} \mathrm{SE}\end{array}$ & $\begin{array}{c}\text { 南偏东 } 25 \text { 度 } \\
25^{\circ} \mathrm{SE}\end{array}$ & $\begin{array}{c}\text { 南偏东 } 25 \text { 度 } \\
25^{\circ} \mathrm{SE}\end{array}$ & $\begin{array}{c}\text { 北偏西 } 80 \text { 度 } \\
80^{\circ} \mathrm{NW}\end{array}$ & $\begin{array}{c}\text { 正西 } \\
\text { W }\end{array}$ & $\begin{array}{c}\text { 北偏西60度 } \\
60^{\circ} \mathrm{NW}\end{array}$ & $\begin{array}{c}\text { 南偏东 } 55 \text { 度 } \\
55^{\circ} \mathrm{SE}\end{array}$ & $\begin{array}{c}\text { 正北 } \\
\mathrm{N}\end{array}$ & $\begin{array}{c}\text { 南偏西70度 } \\
70^{\circ} \mathrm{SW}\end{array}$ \\
\hline 坡度 Slope $\left(^{\circ}\right)$ & 35 & 45 & 47 & 35 & 16 & 37 & 32 & 36 & 32 \\
\hline 平均胸径 Mean $D B H(\mathrm{~cm})$ & 8.9 & 9.2 & 8.9 & 17.0 & 17.4 & 14.6 & 16.1 & 19.2 & 18.9 \\
\hline 最大胸径 $D B H_{\max }(\mathrm{cm})$ & 25.9 & 24.5 & 26.1 & 42.7 & 75.8 & 44.6 & 90.7 & 74.5 & 71.6 \\
\hline 平均树高 Mean Height (m) & 7.7 & 7.7 & 7.5 & 10.6 & 13.7 & 9.9 & 8.1 & 11.7 & 9.9 \\
\hline 最大树高 $H^{2} i g h t_{\max }$ (m) & 12 & 12 & 13 & 16 & 25 & 21 & 17 & 23 & 24 \\
\hline 总胸高断面积 $T B A\left(\mathrm{~m}^{2} \cdot \mathrm{hm}^{-2}\right)$ & 24.7 & 25.1 & 27.5 & 41.4 & 65.0 & 52.5 & 79.0 & 49.3 & 63.2 \\
\hline 密度 Stand density $\left(\right.$ No. $\left.\cdot \mathrm{hm}^{-2}\right)$ & 3200 & 3167 & 3483 & 1500 & 1850 & 2300 & 1800 & 1000 & 1400 \\
\hline 乔木种数 Number of trees & 21 & 19 & 23 & 17 & 19 & 24 & 18 & 21 & 19 \\
\hline 灌木种数 Number of shrubs & 48 & 52 & 44 & 49 & 70 & 70 & 47 & 52 & 55 \\
\hline 草本种数 Number of herbs & 27 & 20 & 24 & 22 & 23 & 25 & 15 & 22 & 24 \\
\hline
\end{tabular}

$\overline{D B H}$, diameter at breast of $1.3 \mathrm{~m}(\mathrm{~cm}) ; D B H_{\max }$, the maximum $D B H(\mathrm{~cm}) ; H_{e i g h t} t_{\max }$, the maximum tree height $(\mathrm{m}) ; T B A$, tree basal area at breast height $\left(\mathrm{m}^{2} \cdot \mathrm{hm}^{-2}\right)$. 
表2 乔木层树种生物量方程

Table 2 Allometric equations for calculating aboveground biomass (AGB) and belowground biomass (BGB) of dominant tree species in this study

\begin{tabular}{|c|c|c|c|c|}
\hline 物种 Species & 地上生物量 $A G B(\mathrm{~kg})$ & 地下生物量 $B G B(\mathrm{~kg})$ & $\begin{array}{l}\text { 本文主要对应树种 } \\
\text { Species in this study }\end{array}$ & $\begin{array}{l}\text { 参考文献 } \\
\text { References }\end{array}$ \\
\hline 雉属 Castanopsis & $\begin{aligned} A G B= & 0.0177\left(D^{2} H\right)^{1.0168}+0.0364\left(D^{2} H\right)^{0.6530}+ \\
& 0.1533\left(D^{2} H\right)^{0.2948}\end{aligned}$ & $B G B=0.00911\left(D^{2} H\right)^{0.933951}$ & 雉属 Castanopsis & Qiu et al., 1984 \\
\hline 水青冈属 Fagus & $\begin{aligned} A G B= & 0.0125\left(D^{2} H\right)^{1.05}+0.000933\left(D^{2} H\right)^{1.23}+ \\
& 0.000294\left(D^{2} H\right)^{1.20}\end{aligned}$ & $B G B=0.00322\left(D^{2} H\right)^{1.13}$ & 亮叶水青冈 Fagus lucida & Wang et al., 2007 \\
\hline 樟科 Lauraceae & $\begin{aligned} A G B= & 0.055603\left(D^{2} H\right)^{0.850193}+ \\
& 0.014757\left(D^{2} H\right)^{0.808395}+ \\
& 0.006652\left(D^{2} H\right)^{1.051841}+ \\
& 0.059871\left(D^{2} H\right)^{0.574327}\end{aligned}$ & $B G B=0.184736\left(D^{2} H\right)^{0.616421}$ & 木姜子属 Litsea & Yao et al., 2003 \\
\hline $\begin{array}{l}\text { 枫香 } \\
\text { Liquidambar } \\
\text { formosana }\end{array}$ & $\begin{aligned} A G B= & 0.174\left(D^{2} H\right)^{0.7661}+3 \times 10^{-8}\left(D^{2} H\right)^{2}+ \\
& 0.001\left(D^{2} H\right)+9.7883+0.0002\left(D^{2} H\right)^{1.2696}+ \\
& 0.0002 D^{3.2304}+3 \times 10^{-7}\left(D^{2} H\right)^{1.5626}\end{aligned}$ & $B G B=0.0094\left(D^{2} H\right)^{0.9538}$ & $\begin{array}{l}\text { 枫香树 } \\
\text { Liquidambar formosana }\end{array}$ & Ming et al., 2012 \\
\hline 柯属 Lithocarpus & $\begin{aligned} A G B= & 0.0347\left(D^{2} H\right)^{0.9470}+0.0084\left(D^{2} H\right)^{0.9112}+ \\
& 0.0072\left(D^{2} H\right)^{0.6893}\end{aligned}$ & $B G B=0.01534\left(D^{2} H\right)^{0.95121}$ & 柯属 Lithocarpus & Qiu et al., 1984 \\
\hline $\begin{array}{l}\text { 木兰科 } \\
\text { Magnoliaceae }\end{array}$ & $\begin{aligned} A G B= & 0.502921\left(D^{2} H\right)^{0.56821}+ \\
& 0.007183\left(D^{2} H\right)^{0.92191}+0.02252\left(D^{2} H\right)^{0.62601}\end{aligned}$ & $B G B=0.0364\left(D^{2} H\right)^{0.79111}$ & 木兰属 Magnolia & Qiu et al., 1984 \\
\hline $\begin{array}{l}\text { 落叶阔叶树 } \\
\text { Deciduous } \\
\text { broad-leaved trees }\end{array}$ & $\begin{aligned} A G B= & 0.0650\left(D^{2} H\right)^{0.84}+1.59\left(D^{2} H\right)^{0.38}+ \\
& 0.218\left(D^{2} H\right)^{0.34}\end{aligned}$ & $B G B=0.291\left(D^{2} H\right)^{0.55}$ & $\begin{array}{l}\text { 鹅耳枥属 Carpinus, } \\
\text { 槭属 Acer }\end{array}$ & Wang et al., 2007 \\
\hline $\begin{array}{l}\text { 常绿阔叶树 } \\
\text { Evergreen } \\
\text { broad-leaved trees }\end{array}$ & $\begin{aligned} A G B= & 0.17686\left(D^{2} H\right)^{0.75995}+ \\
& 0.11499\left(D^{2} H\right)^{0.69997}+0.107513\left(D^{2} H\right)^{0.53231}\end{aligned}$ & $B G B=0.095827\left(D^{2} H\right)^{0.7165}$ & $\begin{array}{l}\text { 青冈属 Cyclobalanopsis, } \\
\text { 冬青属 Ilex }\end{array}$ & Deng et al., 2000 \\
\hline $\begin{array}{l}\text { 落叶小乔木 } \\
\text { Small deciduous trees }\end{array}$ & $\begin{aligned} A G B= & 0.0434\left(D^{2} H\right)^{0.91}+ \\
& 0.000902\left(D^{2} H\right)^{1.31}+0.000790\left(D^{2} H\right)^{1.05}\end{aligned}$ & $B G B=0.000781\left(D^{2} H\right)^{1.05}$ & $\begin{array}{l}\text { 尖叶四照花 } \\
\text { Dendrobenthamia angustata, } \\
\text { 贵州桤叶树 } \\
\text { Clethra kaipoensis }\end{array}$ & Wang et al., 2007 \\
\hline $\begin{array}{l}\text { 常绿小乔木 } \\
\text { Small evergreen trees }\end{array}$ & $\begin{aligned} A G B= & 0.190\left(D^{2} H\right)^{0.663}+ \\
& 0.123\left(D^{2} H\right)^{1.023}+0.00728\left(D^{2} H\right)^{0.548}\end{aligned}$ & $B G B=0.0557\left(D^{2} H\right)^{0.622}$ & $\begin{array}{l}\text { 川桂 Cinnamomum wilsonii, } \\
\text { 杜鹃属 Rhododendron }\end{array}$ & Wang et al., 2007 \\
\hline
\end{tabular}

$D$ 和 $H$ 分别为胸径 $(\mathrm{cm})$ 和树高 $(\mathrm{m})$ 。

$D$ and $H$ are diameter at breast height $(\mathrm{cm})$, and height $(\mathrm{m})$ of a tree, respectively.

Perkin-Elmer, Boston, USA)分别测定地上与地下部 分的碳含量, 结合生物量计算灌木层和草本层的碳 密度。

\subsection{3 木质残体和调落物碳储量}

将木质残体区分为细木质残体(大头直径 $2-10 \mathrm{~cm}$; FWD) 和粗木质残体 (大头直径 $\geqslant 10 \mathrm{~cm} ; \mathrm{CWD}$ ) (Harmon et al., 1986)。测量样方内所有枯立木的胸 径和高度；对倒木记录其两头和中间的直径、长度， 以及腐朽程度(1-4, Zhu et al., 2017b)。倒木和枯立 木体积按以下公式计算:

$$
\text { Volume }=\pi d^{2} L / 4
$$

其中 $d$ 为枯立木胸径或倒木两端和中心的平均直径, $L$ 为倒木的长度 $(m)$ 或枯立木的高 $(\mathrm{m})$ 。采集不同腐朽 程度的枯倒木样品(每株枯倒木取3段木段), 带回实 验室烘干至恒质量后测量干质量, 研磨过篮后测定 碳含量。计算采样枯倒木体积与干质量的关系, 由 此推算样地内枯倒木的干质量与碳密度。

对样方内所有FWD进行收集并称质量。在样方 内随机设置 3 个 $1 \mathrm{~m} \times 1 \mathrm{~m}$ 小样方, 收集小样方内所有
调落物(包括落叶、树皮、果实、直径 $<2 \mathrm{~cm}$ 的枯枝 以及地表其他植物残体)并称质量。每个 $600 \mathrm{~m}^{2}$ 样方 内, FWD与调落物各取3份样品, 带回实验室烘干 $\left(65{ }^{\circ} \mathrm{C}\right)$ 至恒质量后测定含水率，并换算其干质量, 研磨过0.15 mm篎后测定碳含量(Zhu et al., 2017a, 2017b)。

\subsection{4 土壤碳储量}

在样方内随机挖取 3 个土壤剖面, 以 $10 \mathrm{~cm}$ 为间 隔分层, 取到实际土壤深度(约30 $\mathrm{cm}$, 即 0-10、 10-20和 20-30 cm 分3层取样)。每层取两份土壤样 品。其中一份使用环刀 $\left(100 \mathrm{~cm}^{3}\right.$, 直径 $50.5 \mathrm{~mm}$, 高 $50 \mathrm{~mm}$ )取样, 采用 $105{ }^{\circ} \mathrm{C}$ 烘干 $48 \mathrm{~h}$ 后测定各层土壤 容重; 另一份取约 $300 \mathrm{~g}$ 鲜土, 在室温(约 $25{ }^{\circ} \mathrm{C}$, 两 周)自然风干，去除杂质后研磨过篮 $(0.15 \mathrm{~mm})$, 用 元素分析仪测定土壤碳含量。

\section{3 数据分析}

采用单因素方差分析和多重比较(最小显著差 异法)探讨不同林龄亮叶水青冈林生态系统各组分 碳储量的差异。 


\section{2 结果}

\section{1 不同林龄水青冈林生态系统各组分碳储量}

\subsection{1 植被碳储量}

不同演替阶段亮叶水青冈林的植被碳密度分别 为 $(60.2 \pm 7.5) \mathrm{Mg} \cdot \mathrm{hm}^{-2}$ (33年林)、 $(211.1 \pm 87.5)$ $\mathrm{Mg} \cdot \mathrm{hm}^{-2}$ (82年林)和 $(396.6 \pm 150.8) \mathrm{Mg} \cdot \mathrm{hm}^{-2}$ (208年 林), 其中乔木层占据植被碳密度最主要的部分 $\left((58.0 \pm 7.0)-(394.0 \pm 149.6) \mathrm{Mg} \cdot \mathrm{hm}^{-2}, 96.3 \%-\right.$ $99.3 \%)$, 其次为灌木层 $((2.0 \pm 0.9)-(2.5 \pm 1.4)$ $\left.\mathrm{Mg} \cdot \mathrm{hm}^{-2}, 0.6 \%-3.5 \%\right)$, 草本层所占比例最小 $((0.01$ $\left.\pm 0.005)-(0.06 \pm 0.02) \mathrm{Mg} \cdot \mathrm{hm}^{-2},<0.1 \%\right)$ (图1A)。从 33 年林到208年林, 亮叶水青冈林生物量碳密度显 著增加 $(F=19.3, p=0.003)$, 其中乔木层碳储量随 林龄的增加而显著增加 $(F=19.5, p=0.003)$, 而灌木 层和草本层碳储量无显著变化 $($ 图 $1 \mathrm{~A})$ 。在生物量碳 储量的分配上, 地上部分碳储量占总储量的主要部 分 $\left((47.8 \pm 6.0)-(301.9 \pm 109.9) \mathrm{Mg} \cdot \mathrm{hm}^{-2}, 76.1 \%-\right.$ $79.4 \%)$ 。随着林龄的增加, 植被地上 $(F=20.6, p=$ $0.003)$ 与地下 $(F=15.9, p=0.005)$ 部分碳储量都显著 增加(图1B)。

\subsection{2 调落物和木质残体碳储量}

不同演替阶段亮叶水青冈林的植物残体(调落 物 + 木质残体 $)$ 碳储量为 $(1.4 \pm 0.2)-(4.8 \pm 2.5)$ $\mathrm{Mg} \cdot \mathrm{hm}^{-2}$, 其中木质残体碳储量为 $(0.5 \pm 0.1)-(3.2$ $\pm 2.6) \mathrm{Mg} \cdot \mathrm{hm}^{-2}$, 调落物碳储量为 $(0.9 \pm 0.3)-(1.6 \pm$
0.2) $\mathrm{Mg} \cdot \mathrm{hm}^{-2}$ 。随着演替的进行, 植物残体的碳储量 显著增加 $(F=8.7, p=0.021$; 图 $2 \mathrm{~A})$, 其中调落物 $(F$ $=8.0, p<0.05)$ 和木质残体 $(F=5.74, p=0.05)$ 的碳 储量在208年亮叶水青冈林中最高(分别为 $(1.6 \pm 0.2)$ $\mathrm{Mg} \cdot \mathrm{hm}^{-2}$ 和 $\left.(3.2 \pm 2.6) \mathrm{Mg} \cdot \mathrm{hm}^{-2}\right)$, 而在33年林中最低 (分别为 $(0.9 \pm 0.3) \mathrm{Mg} \cdot \mathrm{hm}^{-2}$ 和 $(0.5 \pm 0.1) \mathrm{Mg} \cdot \mathrm{hm}^{-2}$ ) (图2A)。木质残体中, 粗木质残体 $(F=5.7, p<0.05$ ) 碳储量在208年林中最高 $\left((2.87 \pm 2.61) \mathrm{Mg} \cdot \mathrm{hm}^{-2}\right)$, 在33年林中最低 $\left((0.07 \pm 0.04) \mathrm{Mg} \cdot \mathrm{hm}^{-2}\right)$, 而细木质 残体碳储量无明显变化(图2A)。随着演替的进行, 植物残体中调落物所占比例逐渐降低; 而木质残体 比例逐渐增加, 且主要由粗木质残体贡献(图2B)。

\subsection{3 土壤碳储量}

不同演替阶段亮叶水青冈林的土壤碳储量分别 为 $(125.3 \pm 39.0) \mathrm{Mg} \cdot \mathrm{hm}^{-2}$ (33年林)、 $(52.1 \pm 6.6)$ $\mathrm{Mg} \cdot \mathrm{hm}^{-2}$ (82年林)和 $(113.8 \pm 32.5) \mathrm{Mg} \cdot \mathrm{hm}^{-2}$ (208年 林)(图3A)。在土壤碳储量的垂直分配上, 表层 $(0-10$ $\mathrm{cm})$ 土壤碳储量所占比重最大 $(43.5-44.3 \%$; 图3B); 在33年和 82 年林中, 表层土壤碳储量皆显著大于下 层土壤 $(p<0.05)$ 。在不同演替阶段, 土壤总碳储量 及10-20 cm和20-30 cm土壤碳储量皆无显著变化; 而表层土壤碳储量在33年林中最高, 82 年林中最低 (图3A)。随演替进行, 表层土壤碳储量比重基本保 持不变(林龄从低到高依次为 $44.3 \% 、 44.0 \%$ 和 $43.5 \%$ ), $10-20 \mathrm{~cm}$ 土壤碳储量所占比重略有降低(依次从 $34.4 \%$ 降至27.8\%、23.9\%), 而20-30 cm土壤碳储量
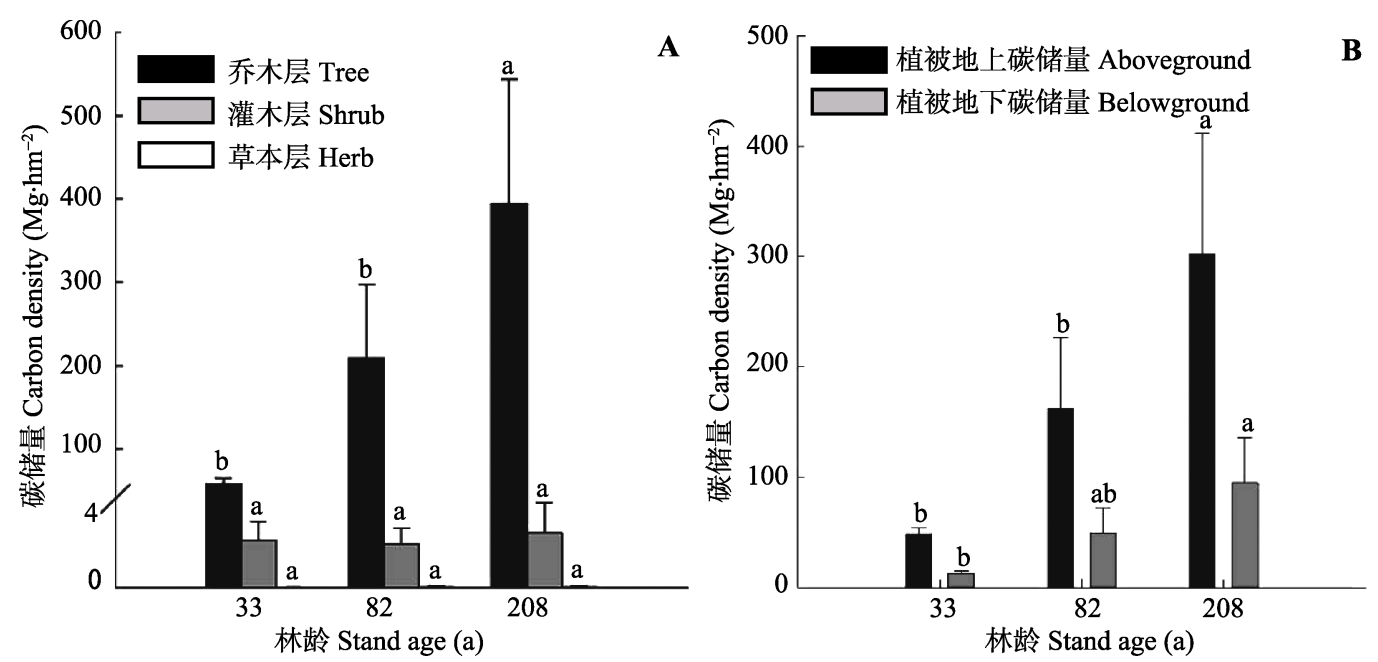

图1 不同演替阶段月亮山亮叶水青冈林不同植被组成的碳储量(平均值+标准误差)。 $\mathbf{A}$, 不同生活型碳储量。 $\mathbf{B}$, 植被地上碳 储量和地下碳储量。

Fig. 1 Changes in vegetation carbon density of the nine successional Fagus lucida forests in Mt. Yueliang (mean $+S E)$. A, Carbon density in different life forms (trees, shrubs and herbs). B, Above- and below-ground carbon density. 

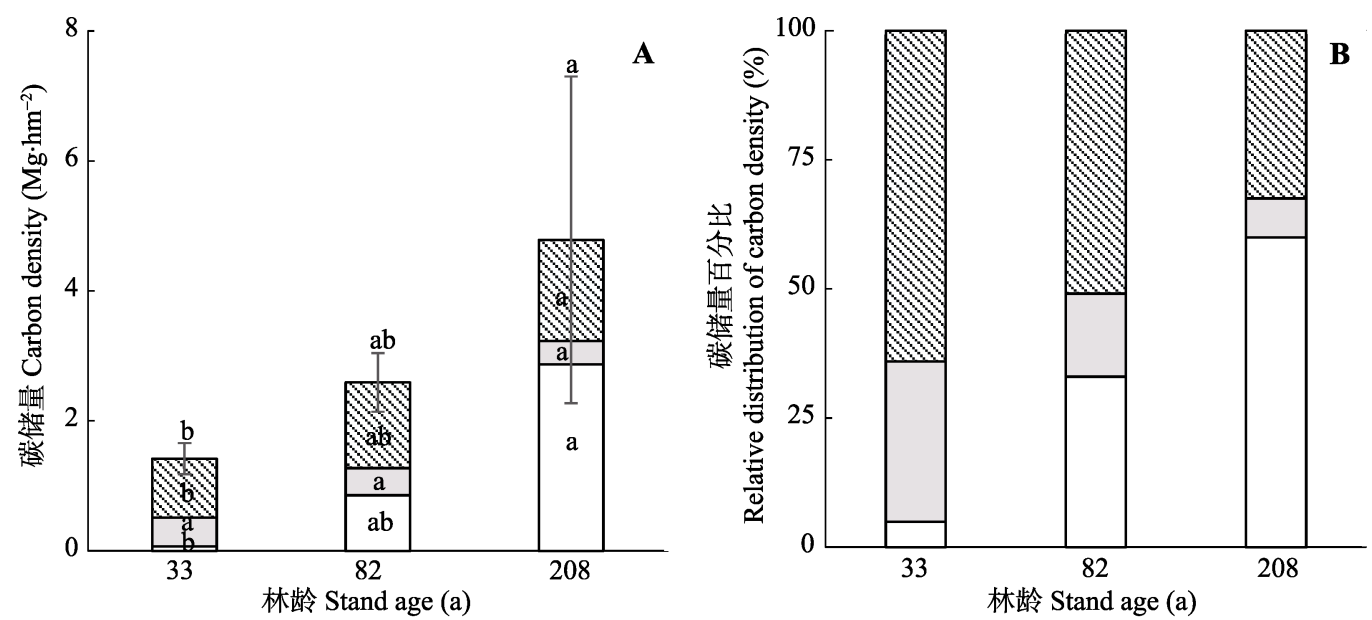

专调落物 Litter

细木质残体 FWD

图2 不同演替阶段亮叶水青冈林调落物和木质残体的碳储量。 $\mathbf{A}$, 植物残体碳储量绝对值(平均值+标准误差)。 $\mathbf{B}$, 植物残体 碳储量相对值。

Fig. 2 Absolute (mean + SE) (A) and relative distribution of carbon density (B) of plant debris in the nine successional Fagus lucida forests in Mt. Yueliang. CWD, coarse woody debris; FWD, fine woody debris.
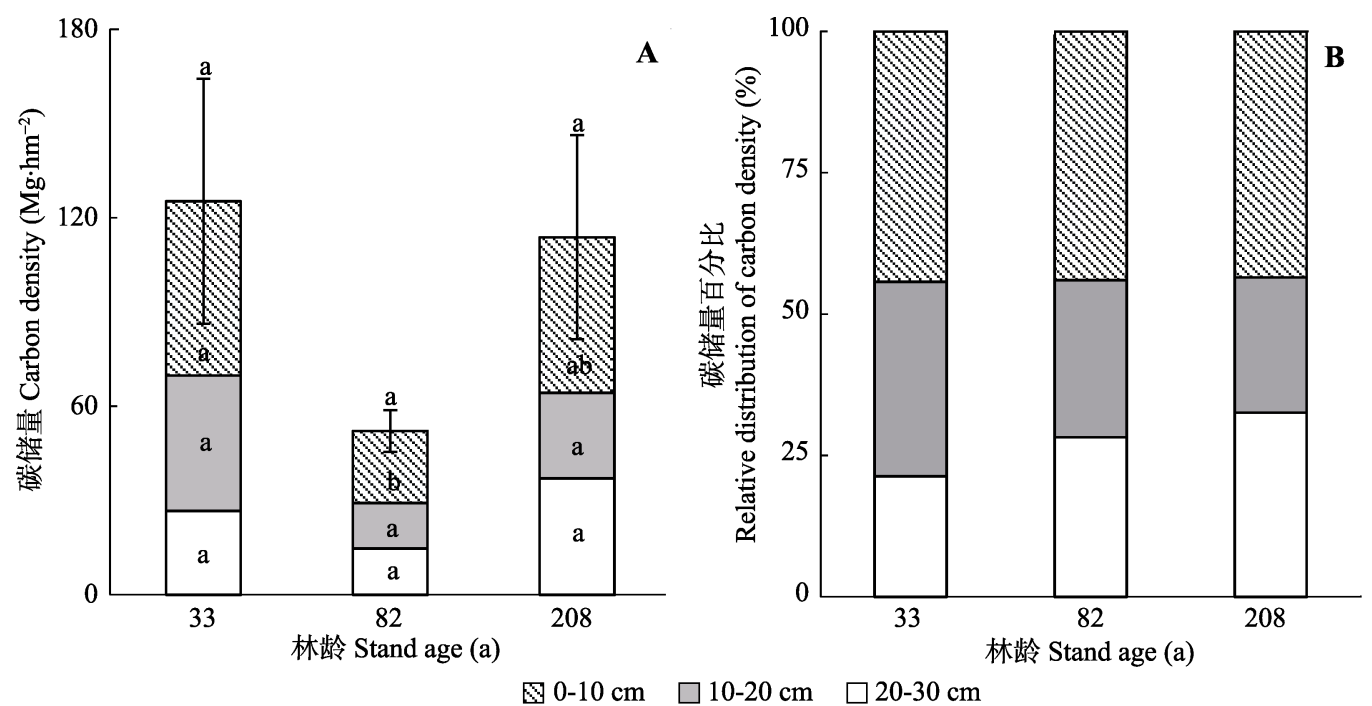

图3 不同演替阶段亮叶水青冈林土壤碳储量。A, 土壤碳储量绝对值(平均值+标准误差)。 $\mathbf{B}$, 土壤碳储量相对值。

Fig. 3 Absolute (mean $+S E$ ) (A) and relative distribution of soil carbon density (B) by soil depth in the nine successional Fagus lucida forests of Mt. Yueliang.

比重略有增加(依次从 $21.3 \%$ 增加至 $28.2 \% 、 32.6 \%$ ) (图3B)。

\section{2 生态系统碳储量分配格局}

不同演替阶段亮叶水青冈林生态系统碳储量总 量分别为 $(186.9 \pm 46.0) \mathrm{Mg} \cdot \mathrm{hm}^{-2}$ (33年林)、(211.1 \pm $87.5) \mathrm{Mg} \cdot \mathrm{hm}^{-2}$ (82年林)和(515.1 \pm 176.4$) \mathrm{Mg} \cdot \mathrm{hm}^{-2}$ (208年林), 主要由植被碳储量(占32.2\%-79.4\%)和 土壤碳储量(占19.6-67.0\%)贡献(图4)。调落物与木 质残体碳储量的贡献几乎可以忽略不计 $(<1 \%$ ) (图 4)。生态系统碳储量总量在208年亮叶水青冈林中最 高, 而在33年林中最低 $(F=10.7, p<0.05$; 图4A); www.plant-ecology.com
其分配格局也随林龄的变化而改变。33年林中，生 态系统碳储量主要由土壤贡献(占67.0\%), 而82年和 208年亮叶水青冈林中生态系统碳储量主要由植被 贡献(分别占79.4\%和78.8\%)(图4B)。调落物和木质 残体碳储量的比例变化较小(图4B)。

\section{3 讨论}

\section{1 植被碳储量}

林龄是影响森林生态系统碳储量的重要因素 (Chapin et al., 2002; Pregitzer \& Euskirchen, 2004)。 植被碳储量随演替进行而增加的现象在针叶林、温 

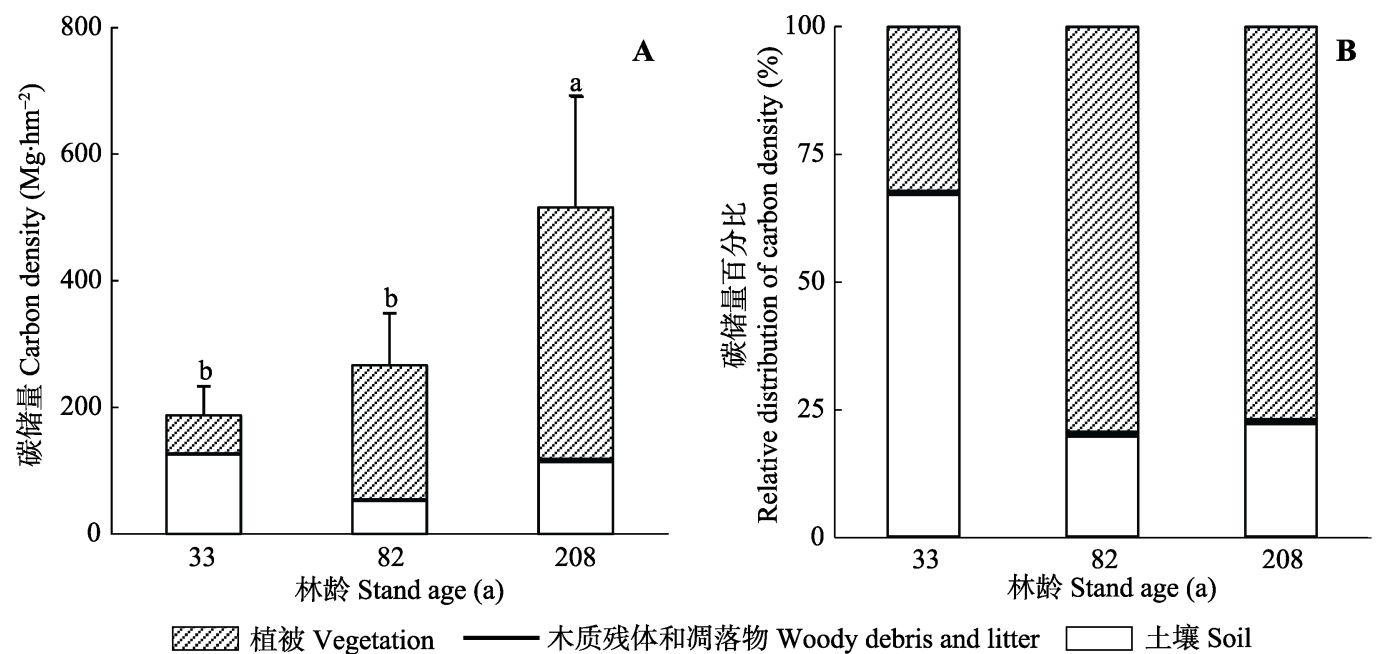

图4 不同演替阶段亮叶水青冈林生态系统碳储量。A, 生态系统碳储量绝对值(平均值+标准误差)。 $\mathbf{B}$, 生态系统碳储量相对值。 Fig. 4 Absolute (mean + SE) (A) and relative distribution of ecosystem carbon density (B) in the nine successional Fagus lucida forests of Mt. Yueliang.

带和热带地区的天然林与人工林中普遍存在(Pregitzer \& Euskirchen, 2004; 唐旭利和周国逸, 2005; Noh et al., 2010; Li et al., 2011; 付威波等, 2014; Zhu et al., 2017b)。本研究中, 月亮山亮叶水青冈林植被 碳储量随林龄增长亦显著增加; 其中乔木层是亮叶 水青冈林植被碳储量的主要贡献者, 且其比例随林 龄增长而增加, 这与以往研究的结果(Peichl \& Arain, 2006; Bradford \& Kastendick, 2010)也相似。

而不同演替阶段亮叶水青冈林的灌木层与草本 层碳储量皆无显著差异。有关林下生物量随林龄增 长的变化趋势目前并无一致的结论。一些研究发现, 在幼龄林阶段, 林下生物量随林龄增长而降低; 而 此后林龄进一步增长时(约 40 年以后), 林下层生物 量基本无明显变化趋势，如美国明尼苏达州北部 7-160年 Pinus resinosa 林和 6-133 年杨树 (Populus tremuloides和 $P$. grandidentata) 林(Bradford \& Kastendick, 2010)。也有研究发现, 一定林龄范围内, 灌 木层生物量随林龄增加而增长, 而草本层相反, 如 2-65年北美乔松林(P. strobus)(Peichl \& Arain, 2006), 韩国8-51年红松林(P. koraiensis)(Li et al., 2011)等。 而在7-32年格木林中, 林下生物量沿林龄序列先增 加后减少(明安刚等, 2014)。林下生物量与乔木层郁 闭度密切相关, 通常随郁闭度增加而减小 (Sigurdsson et al., 2005)。本研究中, 不同演替阶段 亮叶水青冈林郁闭度接近, 故灌木层与草本层碳储 量无显著差异。此外, 林下生物量还受到土壤养分 状况、干扰和管理方式等多种因素的影响(Peichl \&
Arain, 2006)。

\section{2 调落物与木质残体碳储量}

随林龄增长, 木质残体碳储量呈增加趋势, 这 与我国森林整体(Zhu et al., 2017b)以及大兴安岭落 叶松林(Zhu et al., 2017a)的研究结果一致。而以往的 研究多报道木质残体碳储量随林龄增加呈U型变化 (Spies et al., 1988; Sturtevant et al., 1997; Pregitzer \& Euskirchen, 2004), 主要是因为调查的森林演替多 起源于火烧等重大干扰, 因而幼龄林中残留有较多 的木质残体(Spies et al., 1988; Pregitzer \& Euskirchen, 2004; Zhu et al., 2017b)。

有关凋落物随林龄的变化趋势, 不同研究的结 果不尽相同。如全球200年以下温带森林(Pregitzer \& Euskirchen, 2004)与北美7-160年Pinus resinosa林 (Bradford \& Kastendick, 2010)地表有机质层碳储量 都随林龄增长呈增加趋势。研究者认为这可能是由 于幼龄林中调落物被收获或干扰较大从而加速了调 落物分解(Jandl et al., 2007; Bradford \& Kastendick, 2010)。也有研究报道调落物碳储量与林龄无关, 如 北美6-133年杨树林(Bradford \& Kastendick, 2010) 和大兴安岭15-138年落叶松林(Zhu et al., 2017a)等, 其原因可能是调落物的分解速率相对较快, 因而能 较快地达到输入与输出之间的平衡(Peichl \& Arain, 2006; Bradford \& Kastendick, 2010)。此外, 调落物碳 储量随林龄的变化与森林类型也有关(Bradford \& Kastendick, 2010)。植物残体碳储量表征植物残体产 量与其分解量的动态平衡(Zhu et al., 2017b)。本研 
究中, 随演替的进行, 植被碳储量显著增加, 导致 调落物和木质残体的产量也随之增加; 而由于 33 年 林为砍伐后次生, 木质残体与调落物层受人为干扰 和破坏较大，增加了其流失和分解的速率(Bradford \& Kastendick, 2010)。因而33年林中木质残体与调落 物的碳储量都低于 82 年和 208 年亮叶水青冈林。

\section{3 土壤碳储量}

在一定林龄范围内, 随林龄增加, 森林土壤通 常表现为碳积累过程, 即土壤碳储量一般呈增加趋 势(Hooker \& Compton, 2003; Pregitzer \& Euskirchen, 2004; Zhu et al., 2017b)。然而林龄对土壤碳积累的 作用可能受到多种因素的影响, 其中最重要的影响 因子包括土地利用历史、气候和植被类型(Paul et al., 2002; Peichl \& Arain, 2006)。因而, 也有研究报道在 农田或弃耕地上造林的森林土壤碳储量与林龄无显 著关系(Peltoniemi et al., 2004), 或随林龄增长先降 低后增加, 其中 $0-10 \mathrm{~cm}$ 土壤碳储量约 30 年后才可 以恢复到造林前的水平(Paul et al., 2002)。

本研究中, 不同演替阶段亮叶水青冈林土壤总 碳储量无显著差异; 而0-10 cm 土壤碳储量在33年 林最高, 82 年林最低。这种变化格局可能与研究样地 的土地利用历史有关(Paul et al., 2002; Pregitzer \& Euskirchen, 2004; Peichl \& Arain, 2006)。33年亮叶水 青冈林为砍伐后次生, 此前该样地原生植被林龄可 能较大, 有较多的碳积累, 故其土壤碳储量值较高。 尽管砍伐等干扰通常会使土壤碳储量减少, 尤其是 表层土, 但一般在一定时间后可以恢复(Paul et al., 2002; Nave et al., 2010)。所以本研究中, 林龄较小的 次生林的土壤碳储量与林龄较大的原始林相当, 甚 至表层土壤碳储量高于林龄较大的样地, 主要取决 于33年林土壤中原有的碳储量较高。此外, 相比于 深层的矿质土壤, 表层土壤更容易受到干扰等因素 的影响, 故其变异也更大(Paul et al., 2002; Peichl \& Arain, 2006; Nave et al., 2010)。因此, 在讨论森林土 壤碳储量随林龄的变化格局时, 原有的土地利用方 式是一个不可忽视的影响因子。

\section{4 生态系统碳储量及其分配}

本研究中, 不同演替阶段亮叶水青冈林生态系 统碳储量从33年林的 $186.9 \mathrm{Mg} \cdot \mathrm{hm}^{-2}$ 增加到 208 年林 的515.1 Mg $\cdot \mathrm{hm}^{-2}$ 。贵州梵净山44-185年水青冈 $(F$. longipetiolata和 F. lucida) 林的生态系统碳储量在 190.7-503.9 Mg $\cdot \mathrm{hm}^{-2}$ 之间(本课题组未发表数据);
德国Thuringia中部30-171年欧洲水青冈(F. sylvatica) 林的碳储量为 $126-413 \mathrm{Mg} \cdot \mathrm{hm}^{-2}$ (Mund, 2004); 而全 球不同林龄 $(\leqslant 200$ year)温带森林的生态系统碳储 量平均值为121-537 $\mathrm{Mg} \cdot \mathrm{hm}^{-2}$ (Pregitzer \& Euskirchen, 2004), 本研究的结果与这些研究的结果较为 接近。

亮叶水青冈林生态系统总碳储量随林龄的增长 主要由植被碳储量贡献, 故随林龄增长, 亮叶水青 冈林植被碳储量比重增加, 而土壤碳储量比重降 低。这与国内外许多亚热带和温带森林的研究结果 一致, 如广西格木林(明安刚等, 2014)、川中丘陵桤 木(Alnus cremastogyne)-柏木(Cupressus funebris)混 交林(吴鹏飞等, 2008)、大兴安岭兴安落叶松林(Zhu et al., 2017a)以及韩国红松林(Li et al., 2011)和北美 乔松林(Peichl \& Arain, 2006)等。亮叶水青冈林生态 系统碳储量的分配比例与相近林龄范围的欧洲水青 冈林和我国一些温带与亚热带森林的分配格局也较 为接近。如德国30-171年欧洲水青冈林植被碳储量 贡献为 $34.4 \%-75.5 \%$, 土壤碳储量占比为 $23.6 \%-$ $62.0 \%$, 调落物碳储量比例不到 $4 \%$ (Mund, 2004)。

\section{5 不确定性}

本研究调查了贵州榕江县月亮山不同演替阶段 的9个亮叶水青冈林生态系统的全组分碳储量及各 组分的相对贡献。可能会给结果带来不确定性的因 素主要有两方面: 一是由于保护区禁止采伐树木, 本研究在估算乔木生物量时利用的是文献中已有的 生物量方程(Zhu et al., 2017a), 尽管尽可能采用相 似树种和相近气候条件下的生物量方程, 但仍可能 给结果带来一定的不确定性。其二, 对乔木层生物 量碳储量, 本研究采用通用的 0.5 作为碳转换系数 (Myneni et al., 2001; Zhu et al., 2015), 这可能与乔 木实际的碳含量有一定的偏差(Li et al., 2011; Ma et al., 2018)。

致谢 感谢北京大学城市与环境学院生态学系的肖 剑、倪晓风在野外调查中的帮助, 以及贵州榕江县 林业局工作人员的协助。

\section{参考文献}

Aplet GH, Vitousek PM (1994). An age-altitude matrix analysis of Hawaiian rain-forest succession. Journal of Ecology, $82,137-147$.

Bradford JB, Kastendick DN (2010). Age-related patterns of 
forest complexity and carbon storage in pine and aspenbirch ecosystems of northern Minnesota, USA. Canadian Journal of Forest Research, 40, 401-409.

Chapin III FS, Matson PA, Mooney HA (2002). Principles of Terrestrial Ecosystem Ecology. Springer-Verlag, New York.

Deng SJ, Liao LP, Wang SL, Gao H, Lin B (2000). Bioproductivity of Castanopsis hysrix-Cyclobalanopsis glaucaMachilus pauhoi community in Huitong, Hunan. Chinese Journal of Applied Ecology, 11, 651-654. [邓仕坚, 廖利 平, 汪思龙, 高洪, 林柏 (2000). 湖南会同红栲-青冈刨花楠群落生物生产力的研究. 应用生态学报, 11 , 651-654.]

Fang JY, Lechowicz MJ (2006). Climatic limits for the present distribution of beech (Fagus L.) species in the world. Journal of Biogeography, 33, 1804-1819.

Fu WB, Peng WX, Song TQ, Zeng FP, Du H, Wen YG, Xu HF (2014). Biomass and its allocation characteristics of Eucalyptus urophylla $\times E$. grandis plantations at different stand ages. Acta Ecologica Sinica, 34, 5234-5241. [付威波, 彭 晚霞, 宋同清, 曾馥平, 杜虎, 温远光, 徐慧芳 (2014). 不同林龄尾巨桉人工林的生物量及其分配特征. 生态 学报, 34, 5234-5241.]

Gong C, Wang SL, Zeng ZQ, Deng SJ, Chen JP, Long KS (2011). Carbon storage and its distribution of evergreen broad-leaved forests at different succession stages in mid-subtropical China. Chinese Journal of Ecology, 30, 1935-1941. [宫超, 汪思龙, 曾掌权, 邓仕坚, 陈建平, 龙康寿 (2011). 中亚热带常绿阔叶林不同演替阶段碳 储量与格局特征. 生态学杂志, 34, 1935-1941.]

Gower ST, Vogel JG, Norman JM, Kucharik CJ, Steele SJ, Stow TK (1997). Carbon distribution and aboveground net primary production in aspen, jack pine, and black spruce stands in Saskatchewan and Manitoba, Canada. Journal of Geophysical Research Atmospheres, 102, 29029-29042.

Harmon ME, Franklin JF, Swanson FJ, Sollins P, Gregory SV, Lattin JD, Anderson NH, Cline SP, Aumen NG, Sedell JR, Lienkaemper GW, Cromack K, Cummins KW (1986). Ecology of coarse woody debris in temperate ecosystems. Advances in Ecological Research, 15, 133-302.

Hooker TD, Compton JE (2003). Forest ecosystem carbon and nitrogen accumulation during the first century after agricultural abandonment. Ecological Applications, 13, 299-313.

IPCC (2013). Intergovernmental Panel on Climate Change 2013. Cambridge University Press, Cambridge.

Jandl R, Lindner M, Vesterdal L, Bauwens B, Baritz R, Hagedorn F, Johnson DW, Minkkinen K, Byrne KA (2007). How strongly can forest management influence soil carbon sequestration? Geoderma, 137, 253-268.

Kakubari Y (1991). Primary productivity changes for a fifteenyear period in a natural beech (Fagus crenata) forest in the Naeba mountains. Journal of the Japanese Forestry Soci- ety, 73, 370-374.

Li X, Yi MJ, Son Y, Park PS, Lee KH, Son Y M, Jeong MJ (2011). Biomass and carbon storage in an age-sequence of Korean pine (Pinus koraiensis) plantation forests in central Korea. Journal of Plant Biology, 54, 33-42.

Ma SH, He F, Tian D, Zou DT, Yan ZB, Yang YL, Zhou TC, Huang KY, Shen HH, Fang JY (2018). Variations and determinants of carbon content in plants: A global synthesis. Biogeosciences Discussions, 15, 1-22.

Ming AG, Jia HY, Tao Y, Lu LH, Su JM, Shi ZM (2012). Biomass and its allocation in a 28 -year-old Mytilaria laosensis plantation in southwest Guangxi. Chinese Journal of Ecology, 31，1050-1056. [明安刚，贾宏炎，陶怡， 卢立华，苏建苗，史作民 (2012). 桂西南28年生米老排 人工林生物量及其分配特征. 生态学杂志, 31 , 1050-1056.]

Ming AG, Jia HY, Tian ZW, Tao Y, Lu LH, Cai DX, Shi ZM, Wang WX (2014). Characteristics of carbon storage and its allocation in Erythrophleum fordii plantations with different ages. Chinese Journal of Applied Ecology, 25, 940-946. [明安刚, 贾宏炎, 田祖为, 陶怡, 卢立华, 蔡 道雄，史作民，王卫霞 (2014). 不同林龄格木人工林碳 储量及其分配特征. 应用生态学报, 25, 940-946.]

Mund M (2004). Carbon Pools of European Beech Forests (Fagus sylvatica) under Different Silvicultural Management. $\mathrm{PhD}$ dissertation, University of Göttingen, Goettingen.

Myneni RB, Dong J, Tucker CJ, Kaufmann RK, Kauppi PE, Liski J, Zhou L, Alexeyev V, Hughes MK (2001). A large carbon sink in the woody biomass of northern forests. Proceedings of the National Academy of Sciences of the United States of America, 98, 14784-14789.

Nave LE, Vance ED, Swanston CW, Curtis PS (2010). Harvest impacts on soil carbon storage in temperate forests. Forest Ecology and Management, 259, 857-866.

Noh NJ, Son Y, Lee SK, Seo KW, Heo SJ, Yi MJ, Lee KH (2010). Carbon and nitrogen storage in an age-sequence of Pinus densiflora stands in Korea. Science China Life Sciences, 53, 822-830.

Pan YD, Birdsey RA, Fang JY, Houghton R, Kauppi PE, Kurz WA, Phillips OL, Shvidenko A, Lewis SL, Canadell JG, Ciais P, Jackson RB, Pacala SW, McGuire AD, Piao SL, Rautiainen A, Sitch S, Hayes D (2011). A large and persistent carbon sink in the world's forests. Science, 333, 988-993.

Paul KI, Polglase PJ, Nyakuengama JG, Khanna PK (2002). Change in soil carbon following afforestation. Forest Ecology and Management, 168, 241-257.

Peichl M, Arain MA (2006). Above- and belowground ecosystem biomass and carbon pools in an age-sequence of temperate pine plantation forests. Agricultural and Forest Meteorology, 140, 51-63. 
Peltoniemi M, Mäkipää R, Liski J, Tamminen P (2004). Changes in soil carbon with stand age-An evaluation of a modelling method with empirical data. Global Change Biology, 10, 2078-2091.

Pregitzer KS, Euskirchen ES (2004). Carbon cycling and storage in world forests: Biome patterns related to forest age. Global Change Biology, 10, 2052-2077.

Qiu XZ, Xie SC, Jing GF (1984). A preliminary study on biomass of Dendrobium candidum in Yunnan Ailaoshan Xujiaba Area. Acta Botanica Yunnanica, 6, 85-92. [邱学忠, 谢寿昌, 荆桂芬 (1984). 云南哀牢山徐家坝地区木果石 栋林生物量的初步研究. 云南植物研究, 6, 85-92.]

Sigurdsson BD, Magnusson B, Elmarsdottir A, Bjarnadottir B (2005). Biomass and composition of understory vegetation and the forest floor carbon stock across Siberian larch and mountain birch chronosequences in Iceland. Annals of Forest Science, 62, 881-888.

Spies TA, Franklin JF, Thomas TB (1988). Coarse woody debris in Douglas-fir forests of western Oregon and Washington. Ecology, 69, 1689-1702.

Sturtevant BR, Bissonette JA, Long JN, Roberts DW (1997). Coarse woody debris as a function of age, stand structure, and disturbance in boreal Newfoundland. Ecological Applications, 7, 702-712.

Tang XL, Zhou GY (2005). Coarse woody debris biomass and its potential contribution to the carbon cycle in successional subtropical forests of Southern China. Acta Phytoecologica Sinca, 29, 559-568. [唐旭利, 周国逸 (2005). 南亚热带典型森林演替类型粗死木质残体贮量及其对 碳循环的潜在影响. 植物生态学报, 29, 559-568.]

Wang XY, Hu D, He JS (2007). Study of the biomass of Cyclobalanopsis glauca and Sharptooth Oak forests in Shennongjia area. Journal of Capital Normal University (Natural Science Edition), 28(2), 62-67. [王向雨, 胡东, 贺金生 (2007). 神农架地区米心水青冈林和锐齿葪柇 林生物量的研究. 首都师范大学学报(自然科学版), 28(2), 62-67.]

Wang ZX, Fujiwara K (2003). A preliminary vegetation study of Fagus forests in central China: Species composition, structure and ecotypes. Journal of Phytogeography and Taxonomy, 51, 137-157.

Wu KC, Wang DJ, Feng BX (2013). Characteristics and diversity of plant communities in the Moon Mountain in Rongjiang. Guizhou Agricultural Sciences, 41(8), 23-27. [吴开 岑, 王定江, 冯邦贤 (2013). 榕江月亮山植物群落的特 征及多样性. 贵州农业科学, 41(8), 23-27.]
Wu PF, Zhu B, Liu SR, Wang XG (2008). Carbon storage and its allocation in mixed alder-cypress plantations at different age stages. Chinese Journal of Applied Ecology, 19, 1419-1424. [吴鹏飞, 朱波, 刘世荣，王小国 (2008). 不 同林龄桤-柏混交林生态系统的碳储量及其分配. 应用 生态学报, 19, 1419-1424.]

Yang YQ (1994). Scientific Survey of the Yueliangshan Forest Area, Guizhou, China. Guizhou Nationality Press, Guiyang. [杨业勤 (1994). 月亮山林区科学考察集. 贵州民 族出版社, 贵阳. ]

Yao YJ, Kang WX, Tian DL (2003). Study of the biomass and productivity of Cinnamomum camphora plantation. Journal of Central South Forestry University, 23, 1-5. [姚迎 九, 康文星, 田大伦 (2003). 18年生樟树人工林生物量 的结构与分布. 中南林学院学报, 23, 1-5.]

Yu GR, Chen Z, Piao SL, Peng CH, Ciais P, Wang QF, Li XR, Zhu XJ (2014). High carbon dioxide uptake by subtropical forest ecosystems in the East Asian monsoon region. Proceedings of the National Academy of Science of the United States of America, 111, 4910-4915.

Zhang QZ, Wang CK (2010). Carbon density and distribution of six Chinese temperate forests. Scientia Sinica: Vitae, 621-631. [张全智, 王传宽 (2010). 6种温带森林碳密度 与碳分配. 中国科学: 生命科学, 621-631.]

Zhang YB, Lv WQ, Yi WY, Zhou CY, Wu YG, Zhou SQ (2016). Soil stoichiometry characterization of five forest types in Moon Mountain, Guizhou Province. Journal of Tropical and Subtropical Botany, 24, 617-625. [张亚冰, 吕文强，易武英，周传艳，吴永贵，周少奇 (2016). 贵 州月亮山5种森林类型土壤生态化学计量特征研究. 热 带亚热带植物学报, 24, 617-625.]

Zhu JX, Hu XY, Yao H, Liu GH, Ji CJ, Fang JY (2015). A significant carbon sink in temperate forests in Beijing: Based on 20-year field measurements in three stands. Scientia Sinica: Vitae, 58, 1135-1141.

Zhu JX, Hu HF, Tao SL, Chi XL, Li P, Jiang L, Ji CJ, Zhu JL, Tang ZY, Pan YD, Birdsey RA, He XH, Fang JY (2017a). Carbon stocks and changes of dead organic matter in China's forests. Nature Communications, 8, 151. DOI: 10.1038/s41467-017-00207-1.

Zhu JX, Zhou XL, Fang WJ, Xiong XY, Zhu B, Ji CJ, Fang JY (2017b). Plant debris and its contribution to ecosystem carbon storage in successional Larix gmelinii forests in northeastern China. Forests, 8, 191. DOI: 10.3390/f8060191.

特邀编委: 李胜功 责任编辑: 李 敏 